\title{
ENERGY REQUIREMENTS OF EUROPE
}

$\mathrm{T}$ HE report on Europe's future needs of energy recently issued* by the Organization for European Economic Co-operation contains a most interesting examination of the position and includes a number of important recommendations which have been derived from a detailed study by a group of experts. This study has comprised the collection and examination of data and opinions emerging from international organizations and professional circles able to provide the pertinent information.

The report reveals that the consumption of all forms of energy in Europe, which in 1955 was equiv. alent to 730 million tons of coal, is rising so rapidly that in 1975 it is likely to reach a figure equivalent to 1,200 million tons of coal. 'This forecast is based on a maintenance of the competitive position of the member countries of the Organization for European Economic Co-operation in an expanding world economy, and the consequent raising of their standards of living.

According to the report, the share of the total requirements expected to be covered in 1975 by the production of primary energy in Western Europe will amount to an equivalent of 750 million tons of coal, as against 580 million tons in 1955 . It emphasizes that it would be erroneous to believe that nuclear energy will make large contributions to the supply of energy available in Western Europe in the next twenty years. Rather is the limit of this contribution put at 80 million equivalent tons by 1975 , or only 8 per cent of the total requirements. Unless a special effort is made to promote the indigenous production of primary energy, the remaining gap between energy requirements and indigenous supplies would have to be bridged by imports of coal and oil, the cost of which would amount in the target year 1975 to about $£ 1,800$ million at present prices. This may well present a formidable problem for some member countries in its effect on the balance of payments. The dependence of Western Europe on imported energy, with its inherent risks as regards matters of both economics and security, and the certainty of rising prices, must imply the serious need for a determined effort on the part of all member countries to develop further their indigenous production of all forms of energy. All reserves of energy will be needed in the future, and it is important to note that coal will be the mainstay of the energy economy in Europe for many years to come. Further, an increased output of coal must depend on long-term investment, on the development of improved mining methods, and on adequate terms of miners' pay and employment. In effect, coal must be given the outlook of a modernized and stable industry, which will attract able young men to join it. No doubt in time the competitive position of the coal industry may be affected, for after 1975 nuclear energy is expected to free the coal burnt in thermal power stations to an increasing extent. Nevertheless, this coal will be needed for other purposes for which nuclear energy cannot replace it. Meanwhile, the ultimate importance of nuclear

* Europe's Growing Needs of Energy: How can they be Met? A Report prepared by a Group of Experts. Pp. 120. (Paris: Organization for European Economic Co-operation; London: H.M. Stationery Office, 1956.) 400 francs; 8 s. ; 1.25 dollars. energy and the difficult and novel problems involved in its development should induce member countries, both jointly and individually, to make a large and technological effort in the nuclear field. Additional effort will be necessary in the harnessing of undeveloped sources of hydro-power and for new sources of oil and natural gas.

The share of oil in supplying the energy needs of Western Europe must also rise rapidly. The concomitant factors governing this rise are the increasing consumption of oil for transport of all kinds, the advantages of oil for certain purposes and its increasing use as a substitute for coal owing both to its lower cost and to the shortage of coal. The world's reserves of oil will be adequate for this requirement, but large investments must be made by the oil companies in Western Europe as well as abroad.

Special importance is attached to the up-grading. of primary into secondary forms of energy, such as gas and electricity. These latter are essential to a rise in productivity of many industries and are associated with improvements in the standards of living. These secondary forms of energy are the means of utilizing with the greatest efficiency the limited supplies of primary energy, and contribute to their greater adaptability. The fact that they can be produced with the aid of different forms of primary energy introduces an element of flexibility into the energy economy, which serves to lessen the rigidity inherent in the coal industry.

A potent factor in reducing the menacing gap between indigenous production and the overall requirements of energy resides in the still existing possibilities of saving energy by economies at every stage, from its winning and conversion in the energy industries to its final utilization in industry and in the home. The European Productivity Agency of the Organization for European Economic Co-operation is called upon to render assistance in this field, and member countries are urged to institute organized efforts for the purpose of energy saving.

The report urges Governments to give competition full play, in order that the consumer may be able to have maximum choice between the different forms of energy. This requires Governments to establish energy policies suited to their own circumstances, needs and resources in order to deal effectively with the urgent problems in the demand for and the supply of energy. The establishment of such policies should include some co-ordination between the different forms of energy, and be followed by the recommended co-ordination of the separate Governments' energy policies. This would result in increased co-operation at international level. At the same time, it is recommended that Governments should endeavour to avoid legislative or administrative restrictions likely to retard the development of sources of energy, or to jeopardize their efficient utilization. Further, in the framing of overall social, economic and financial policies, due consideration should be given to the effects of taxation, price maxima and wages structures on the efficient production and use of energy.

Other means of co-operation are recommended in this report. There are important chapters on the 
financial aspects of the energy problem; thus in energy prices, the impact of such prices on the balance of payments, and the investment needs of the energy industries in the period under review, are considered. In this context, there is recommended the mutual supply of capital needed for the production of energy as well as the pooling of research and development programmes. Again, it is considered to be of mutual benefit for member countries to increase their co-operation in the fields of exchange of energy, of man-power for the production of energy and of information and experience.

In the final chapter of the main report, it is pointed out that only a cursory examination of the many important general problems envisaged was practicable. More detailed examination was therefore necessary, and it proposes the setting up of a new committee of individuals selected for their experience in this field, to act as advisers to the Organization. Not only should this new committee examine the conclusions of the present report and follow their implementation, but also it should review periodically both energy statistics covering the pertinent factors, and, with the help of the economic and other technical committees, the forecasts of energy requirements and supplies. The terms of reference should also include the search for problems which need further investigation.

Extensive appendixes are attached to the report. They indicate the sources of the information obtained, which covered an authoritative field concerned with trade union and managerial responsibility. The forecasts on which the main conclusions have been based were derived by four independent methods. Assump. tions were made as to the anticipated level of employment, the standard of productivity, the level of working hours and, most important of all, that no abnormal events would intervene, such as a war.

Most valuable to the general interested reader are the reviews of the energy situations in the individual countries concerned, some twelve in number. They give the individual statistics for the various sources of energy as to production, the reserves and future prospects, the most important of the pertinent factors as to imports and exports of energy, and the developmonts in the nuclear field.

Of the primary sources of energy in the period 1956-75 in Western Europe, the annual production of coal may increase, according to present plans, from 480 million tons, as at 1955 , to 520 million tons ; but some further capacity must be provided to replace exhausted pits, to the extent of 190 million tons per annum. These additions will call for investments in the neighbourhood of $£ 3,000$ million, exclusive of coke ovens, pithead power stations and briquetting plant. Lignite, mostly in Germany, will require $£ 570$ million. Water developments to result in an increase of about 150 per cent capacity in 1975 , as compared with 1955 , may cost some $£ 7,600$ million. Indigenous sources of oil and natural gas are less tangible factors to assess, but are expected to require a sum equivalent to that of coal, namely, $£ 3,000$ million.

For the provision of secondary energy, coke and coal gas will require a sum slightly in advance of this last figure, and for thermal electricity the overall investments may amount to the considerable figure of $£ 17,700$ million. This is exclusive of the provision for transmission and distribution of electrical energy. The total investment to cover all requirements in the period 1955-75 could reach the astronomical figure of $£ 50,000$ million, or an annual average of $£ 2,500$ million. The investment provided in 1955 was $£ 1,580$ million. Thus an increase by some 60 per cent of outlay is included in the present plans for development.

The report is illustrated by a number of graphs, relating to the position and the prospects in the United Kingdom, France, Switzerland and Sweden, which emphasize clearly the importance of coal to Great Britain.
R. J. SARJANT

\section{THE MEASUREMENT OF BODY RADIOACTIVITY}

\section{CONFERENCE AT LEEDS}

T 'HE problem of measuring the radioactivity of the human body is exciting interest in many countries. A conference, the first of its kind devoted to this problem, was held during April 16 and 17, in the Department of Medical Physics of the University of Leeds. Delegates attended from Denmark, Sweden, Germany, the United States, Canada, Australia and Great Britain, and they included representatives from almost all the groups known to be engaged in this field.

In a short introduction, Prof. F. W. Spiers outlined the aims of the conference. Of first importance was the bringing together of as many as possible of those actively working on the problem of body radioactivity and others interested directly in it. It was intended to consider particularly the external methods of measuring body $\gamma$-ray emission and their possible limits of sensitivity. High-pressure ionchamber techniques are already adequate, he said, to measure amounts of $\gamma$-emitters in the body of the order of $2 \mathrm{ng}$. radium equivalent ( $1 \mathrm{ng} .=10^{-9} \mathrm{gm}$. ,) that is, well below the recommended maximum permissible levels ${ }^{1}$. An improvement in $\gamma$-sensitivity of ten times appears to be feasible with scintillation techniques, but perhaps the special importance of the latter is in their possible application to measuring very low levels of $\beta$-emitters in the body. The conference would also include consideration of techniques other than external detection giving data on body radioactivity.

Papers were read by representatives of each of the three groups who have used high-pressure ionchamber methods. Dr. B. Hultqvist (Institute of Radiophysics, Stockholm) discussed results obtained at Stockholm using two arrays each of twelve highpressure chambers in a laboratory which, being at 55 metres depth below solid rock, is well shielded from cosmic rays. To exclude local radiation, walls, floor and ceiling are lined with tanks containing Thames water (since this has a considerably lower 